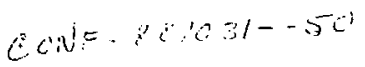

CCRL- 98627

PREPRINT

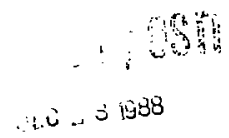

Overview of the ICF 1000 MJ Experiment
Chamber Design

Dennis Slaughter

This paper was prepared for submittal to

Eighth Topical Meeting on the

Technology of Fusion Energy

Salt Lake Cjty, Utah

October 9-13, 1988

REPRODUCED FPOA

September 23, 1988

This is a preprint of a paper intended for pundketion in a jaurnal or proceedings. Since chankes may be mode before publication. this preprint is made arellable with the understanding that it will not be cited of reprodeed without the permission of the author.

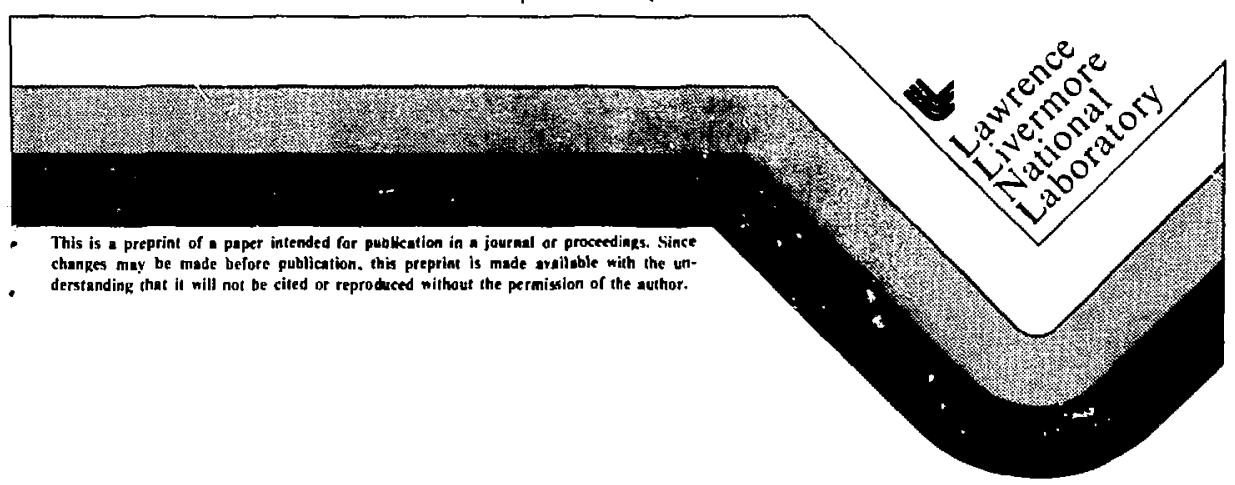




\section{OVERVIEW OF THE ICF 1000 MJ EXPERIMENT CHAMBER DESIGN*}

\author{
Dennis Slaughter \\ Lawrence Livermore National Laboratory \\ P. O. Box 5508, Livermore, California 94550 \\ (415) 422-6425
}

UCRL --98627

DE89 004883

\begin{abstract}
A conceptual design of an experiment chamber for a high gain ICF facility (1000 MI) is being developed. Performance goals have been established. Several design approaches are being evaluated through computer simulations, engineeringanalysis, and experimental testing of candidate first wall components.
\end{abstract}

\section{NTRODUCTJON}

A concepiual design is being developed for the ICF Megajoule Experiment Area (MEA) which is the containment chamber and target support portion of the Laboratory Microfusion Facility (LMF). The objective is a concept which meets all of the performance goals at an acceptable cost and which minimizes technical and safety risks.

Performance goals for the MEA are very stringent. Anticipating $10 \mathrm{M}$ J of laser light at nominally $353 \mathrm{~nm}$ and fusion gain of 100 , the nominal fusion yield is $1000 \mathrm{MJ}$. Variations in target compression ( $\rho R$ ) of a factor of two from predicted values could result in maximum fusion yield of $1400 \mathrm{MJ}$ including $5 \times 10^{20}$ neutrons. Similarly, soft $x$-ray yield is assumed to be as high as $250 \mathrm{M}$ ] and target debris is assumed to camy as much as $250 \mathrm{MJ}$, though nominal full yield values are smaller. These products generate unprecedented loads on the MEA. The 10 ns soft $x$-ray pulse and the target debris contain the energy equivalent of about $100 \mathrm{~kg}$ of high explosive.

Anticipating one full yield shot per week over a 10 year lifetime, the MEA is to be designed for 500 full yield shots. In addition, we anticipate 2000 shots at yields less than $100 \mathrm{MJ}$ and at a rate one per day. Neutron generation during the life of the facility is expected to be about 0.1-0.5 grams.

Structurally, the MEA should withstand the shock generated when the soft $x$-ray pulse produces ablation of the inner wall surface and consequent hydrodynamic loading. In addition there is impulsive loading from target debris and the ablation it produces as well as pressure loading due to the residual hot gas. Finally, the generation of high velocity shrapnel from the target environment and masses associated with military applications experiments poses a serious threat to any first wall design.

"Work performed under the auspices of the U. S. Department of Energy by the Lawrence Livermore National Laboratory under contract number W-7405-ENG-48.
The MEA must also resist buckling stresses due to possible hydrostatic and atmospheric loads as well as seismic loads. Driver propagation requires yacuum pressures lower than $10^{2}$ Torr and diagnostics needed for low yield shots would be difficult at vacuum pressures above $10^{-5}$ Torr. In addition, the MEA should provide for $60-80$ driver penetrations (depending on driver design > up to $60 \mathrm{~cm}$ diameter and up to 100 diagnostic penetrations.

The MEA must support neutron and gamma tay shielding. Design goals are to reduce prompt radiation dose to personnel outside the chamber during a shot, and radiation dose following a shot due to activation to 'evels which do not exreed 100 mrem per working week. Personnel access to the interior of the MEA is desired within one day after a Jow yield shot (less than $10 \mathrm{MJ}$ ) and within one week after a full yield shot. Access will be complicated due to residual tritium (up to $50 \mathrm{mg}$ per shot) and by the need to maintain acceptably Iow radiation dose rates ( 100 mrem/hr for brief servicing requirements and $2.5 \mathrm{mR}$ /hr for major repairs or installation of new equipment).

Finally, provision wilt be made for simulations of weapons radiation fields for the evaluation of military components. Exposure volumes nominally $100 \mathrm{~cm} \times 100 \mathrm{~cm}$ in exposure arca and $50 \mathrm{~cm}$ thick are desired in the immediate vicinity of the target.

\section{DESIGN APPROACH}

For the baseline design, we assume targets which emit $x$ rays in the neighborhood of $1 \mathrm{KeV}$. Figure 1 shows the photon mean free path' (solid lines) for carbon, aluminum, and water frost at density $0.1 \mathrm{gm} / \mathrm{cm}^{3}$. It is clear from the figure that the $x$-ray pulse penetrates only the first few microns of the first wall even if it is constructed of low- $Z$ materials.

The $x$-ray fluence at which a short pulse of $1 \mathrm{keV}$ photons begins to cause permanent damage in many materials of interest for optic and the first wall is $0.5-1.0 \mathrm{~J} / \mathrm{m}^{2}$. Figure 2 shows a plot of $x$-ray fluence at the first wall due to a $250 \mathrm{M}$ ) $f$ ilse vs. the wall radius.

Unprotected first walls of common construction materials such as aluminumor steel must be placed at nearly 60 mradius to avoid vaporization entirely. Even carbon, which is most resistant to vaporization, must be located $30 \mathrm{~m}$ from the target. 
reduces residual gas pressure.

Experimental verification of shockattenuation in frost is not yet complete. The ability to grow a uniform layer in a reasonably short time on a large wall and for that layer to be self supporting in the presence of mechanical shocks or vibration remains to be established. Finally, the stability of the layer over long periods has yet to be demonstrated.

First walls of carton are attractive due to their relative freedom from neutron activation and resistance to vaporization. Carbon-carbon walls consisting of strong carbon fibers weaved into a matrix in two or three dimensions are being studied by Sandia National 'aboratory (K. Wilson, J. Whitley), General Atomics (R. Bourque, K. Schultz), Kaman Sciences (L. Webster), and LLNL (K. Sinz, D. Schauer). These materials are strong when densified by diffusing and pyrolizing carbon into the matrix. A carbon wall erodes when a few microns of the surface vaporizes on each full yield shot. However, recondensation replaces much of the material and residual porosity attenuates propagation of shock pressures and reduces the likeljhood of spall due to the initial ablative shock.

These materials are very expensive in 3-D format and cost considerations may limit their use. The $2-D$ weaves are much less expensive but are vulnerable to delamination during shock loading. In all cases some means of post-shot decontamination of the wall must be demonstrated and recondensation on optics must be evaluated.

Alternatively, shock loading of the permanent first wall may be reduced by introducing high aspect ratio textured surfaces into the wall so that shock waves are generated at large angles with respect to the surface normal of the substrate. A fiber structure resembling a carpet has been studied by $W$. J. Shafer Associates' (M. Monsler, W. Meier) and a surface of steep pyramids has been studied by General Atomics ( $R$. Bourque, $K$. Schul(z). They present a large area, oblique to the $x$-ray flux, so that the areal loading is reduced and the amount of ablated material is less. In addition, the ablation generates a shock directed toward the local surface normal which has a small component directed into the substrate. Consequently, shocks propagating into the permanent first wall are believed to be subslantially reduced in peak pressure.

The protective concepts based on highly structured surfaces are difficult to study through computer simulations. Viability af these concepts will be de' ermined experimentally. . Adequate protection of the permantnt substrate against damaging tensile shock waves must be demonstrated. It must also be shown that these concep's are economical either through inexpensive replacement of the wall or very long useful lifetime with minimal servicing. A method of decontamination of the surface must also be demonstrated.

Our final design may incorporate a staged defense including two or more of these protection concepts.

\section{COMPUTER SIMULATIONS}

Computer simulations have been used to predict shock loading of the first wall for most of the design approaches above. In most cases the calculations indicate no permanent damage to the $\mathrm{MEA}^{3,5,7}$
Computer predictions of shrapnel generation in the area near the target are just beginning at Kaman Sciences and the Stanford Research Institute (SRI). Conclusions are not yet available. Results of these calculations and studies directed toward mitigating the effects of shrapnel generation in both full yield and low yield shots will be critical to the feasibility of our design approach.

Studies directed toward protection of thedriver final optics are also continuing and are presented elsewheres. Material and design choices for the MEA may impact substontially on the feasibility and design choice for protecting the optics. Those interactions are part of our ongoing design effort.

Finally, detailed analysis of the structural design to support the wall, driver beam lines, and neutron shielding is ongoing with computer calculations. Instability due to buckling, bursting due to residual hot gas pressure after a shot, seismic loads, and resonant excitation of chamber fundamental modes by the relatively low frequency loads imposed by target debris and gas pressure loading ane areas of particular concern. Results of these calculations will be important in determination of the material thicknesses and the amount of metal to be included within the neutron/gamma ray shield. There is a contiruing interaction between the need for strength in the chamber and the need to reduce the mass of materials which will undergo neutron activation and restrict personnel access. Hydrocarbons and carbon-carbon composites must be seriously considered for structural components not protected by neutron shielding.

\section{EXPERIMENTS}

Experiments are beginning to determine the shock mitigating properties of several of the first wall design approaches described above and for which computer simulations have shown favorable results.

Gas gun experiments are planned at LLNL and Kaman Sciences to measure attenuation of shocks in aluminum, teflon, and porous alumina over aluminum. In addition, $x$-ray flux simulations are scheduled at the Gamble II facility (NRL) using a proton beam (with some carbon). Figure 1 shows the proton range (dashed curves). (Note that the energy scale is in units of $100 \mathrm{keV}$ for protons). At energies below $1 \mathrm{MeV}$ the energy is deposited at depths comparable to that of soft $x$-ray deposition in the MEA. Proton beams at energies of $600-800 \mathrm{keV}$ are expected to simulate the $x$-ray ablation and consequent shock loading in MEA first wall components at energy densities up to $300 \mathrm{~J} / \mathrm{cm}^{2}$. Samples of aluminum, teflon on aluminum, alumina on aluminum, water frost on aluminum, 2-D carbon fiber weave, 3-D carbon fiber weave, carbon fiber carpet and carbon pyramids will be exposed to these beams. Shock propagation measurements will be made and exposures repeated to assess multiple shot life expectancy.

\section{PERSONNEL ACCESS}

Choice of materials for those components which are placed inside of the neutron shielding is critical in order to meet the goals for personnel access. This issue has ben explored in considerable detail at LLNL ${ }^{10}$ and will be reviewed only bricfly here. Steel construction must be ruled ou tof the interior because of the long lived ${ }^{54} \mathrm{Mn}$ and ${ }^{51} \mathrm{Cr}$ activity produced by neutron irradiation of iron. This is shown in Fig. 3 where the radiation 


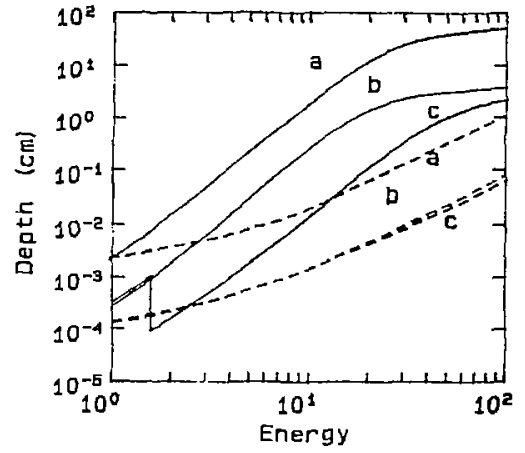

Figure 1. Photon mean free path (solid) where energy is units of $\mathrm{keV}$ and proton range (dashed) where energy is in units of $100 \mathrm{keV}$. Curves are for: a) Water frost at density $0.1 \mathrm{gm} / \mathrm{cm}^{3}$, b) carbon, and c) aluminum.

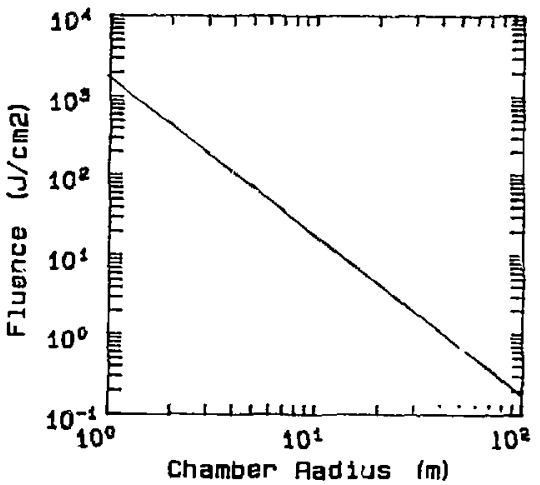

Figure 2. Maximum single shot $x$-ray energy fuence on MEA first wall.

We consider the MEA containment design viable if the construction cost is less than $80 \mathrm{M} \$$, the annual operating cost less than $20 \mathrm{M} \$$, and these goals can be reached without unacceptable safety or tcchnology risks. Cost considerations force the design to incorporate a first wall which is feasible at a radius approximately $5 \mathrm{~m}$. However, Fig. 2 shows the energy fluence on the wall to be about $100 \mathrm{y} / \mathrm{cm}^{2}$ for full yield shots. About 0.1 $\mathrm{MJ} / \mathrm{gm}$ is deposjted in the first few microns of the wall, giving an energy density 25 times larger than that of detonating TNT.

\section{FIRST WALL}

Protection of the MEA permanent first wall may be approached using sacrificial/replaccable shields. Altematively, the first wall may be of a robust design where ablation of the surface is tolerated and occasional repair or resurfacing is fessible. Several of these approaches are discussed in detail in other papers in these proceeding ${ }^{25}$ and elsewhere. Consequently, they will only be discussed qualitatively here.

Target shrouds consisting of $.25 \mathrm{~cm}$ polyethylene or $7 \mathrm{~cm}$ of frozen nitrogen arecurrently being studied at LLNL ${ }^{5,7}$ and at the University of Wisconsin ${ }^{6}$ as a means of reducing or eliminating soft $x$-ray illumination of the permanent first wall. The shroud absorbs the soft $x$-rays as well as target debris and is vaporized in the process. It may be located any distance from the target but, in order to minimize its mass and minimize the probability of shrapnel generation due to incomplete vaporization of the shroud, it is likely to be placed immediately around the target. The shroud provides helpful collimation for diagnostics and, in the case of a frozen nitrogen shroud, it reduces the heat load on cryogenic targets due to thermal radiation from the wall. It also may be used in combination with other protection approaches described below.

Experimental verification of the computer simulations and a demonstration of the fabrication technology have not yet been completed. In particular, the ability of the shroud to expand the time over which znergy is delivered to the MEA first wall and reduce the corresponding flux to a level at which conduction cooling of the wall prevents vaporization has yet to be shown under MEA conditions.

Sacrificial inner layers may be used to protect the permanent first wall. Turee such materials are currently being considered. Kaman Sciences Inc. (L. Webster) is studying plasma spraying of porous alumina over an aluminum wall at room temperature. The alumina, which is made porous by inclusion of small microballoons, attenuates the shock wave produced from ablation of the alumina surface. As a resuit the tensile stresses in the aluminum substrate are greatly reduced and failure of the wail is avoided. Teflon may be used instead of alumina. Both materials have been studied as protection mechanisms for re-entry vehicle nose cones subjected to nuclear weapons radiation and extersive experimental testing demonstrates their shock mitigating effects.

In order for this protection strategy to be viable it must be possible to economically spray the surface layer on a wall at room temperature and, at a later time, be able to economically remove it together with embedded debris for decontamination purposes. These technologies remain to be verified experimentaliy.

Low density water frost may also be used as a sacrificial inner layer. Energy Technology Engineering Center (ETEC) has shown that water frost may be grown at low density on a first wall then cooled to cryogenic temperatures where it is stable and has low vapor pressure ( $10^{-9}$ Torr). This concept is being studied jointly by ETEC (N. Hoffman) and LLNL ${ }^{3}$ (C. Orth, K. Sinz). A $2 \mathrm{~cm}$ thick layer of frost at density $0.1 \mathrm{gm} / \mathrm{cm}^{3}$ absorbs the soit $x$-ray pulse and partially evaporaics. It attenuates the shock pulse to pressures of a few bars at the permanent first wall. After the shot the wall is allowed to warm so that the frost melts and is drained away together with the radioactive debris and tritium. The cold first wall required for frost maintenance also reduces thermat radiation heat load on cryogenic targets by a factor of ten and the post-shot recondensation 
dose rate in the center of the MEA is shown as a function of time after a full yield shot $\left(3.5 \times 10^{20}\right.$ neutrons). The calculation assumes a chamber constructed of a $4 \mathrm{~cm}$ thick SS304 steel at $5 \mathrm{~m}$ radius. Calculations for identical chambers constructed of 5083 aluminum and low activation aluminum (with iton, copper, and mangancse reduced to less than $.001 \%$ ) arealso shown. Several curves are included to indicate the accumulation of radioactivity from a series of nominal full yield shots at the rate one per week. The figure shows dose rate following the first (dots), 25th (dashes) and 500th (solid) shots.

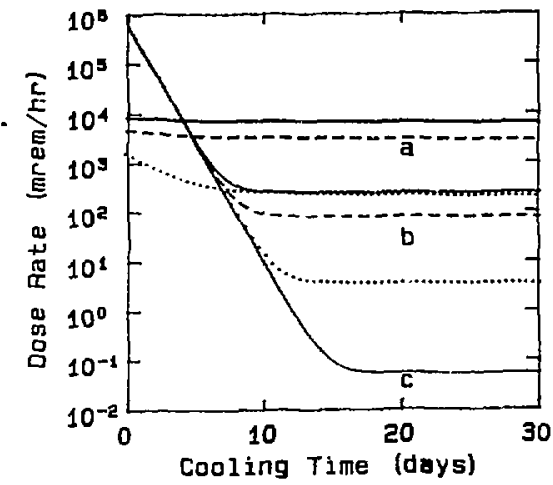

Figure 3. Radiation dose rate inside MEA following a nominil full yield shot for $4 \mathrm{~cm}$ thick first walls at $R=5 \mathrm{~m}$. Curves are for: a) steel (S5304), b) aluminum (5083), and c) low activation aluminum. Results shown are dose rate following first (dottid), 25th (dashed) and 500th (solid) shots.

In an aluminum chamber the radiation dose is dominated for more than a week by ${ }^{2} \mathrm{Na}$ decay due to the ${ }^{7} \mathrm{Al}$ (n, alpha) reaction. At longer times the radiation dose is dominated by manganese, iron and copper impurities present in the aluminum.

Accumulation of long lived activities over the facility lifetime further limits access. Only in the case of an experiment cha:nber construcled of low activation aluminum does the dose rate decay below $100 \mathrm{mrem} / \mathrm{hr}$ within 8 days after the 500 th fuil yicld shot. in a chamber of 5003 aluminum the post shot dose rate does not reach $2.5 \mathrm{mrem} / \mathrm{hr}$ during any reasonable cooling time. Of course the dose rates scale almost linearly with aluminum Inass so that a thinner wall would reduce the dose. But even a wall of low activation aluminum and only $4 \mathrm{num}$ thick has dose rates greater than $100 \mathrm{mrem} / \mathrm{hr}$ until six days after any full yicld shot.

It is important to point out that even low yield shots require long cooling rimes when the chamber is constructed of aluminum. Farly dose rate scales linearly with yield; the figure may be used to show that a shot generating only $1 \%$ of full yield (gain=i) produces post shot dose rates greater than $100 \mathrm{mrem}$ / hr for approximately four days (even if low activation aluminum is used). It appears our goal of one day cooling time after low yicld shots can be met only with a design based on low activation aluminum with thickness no greater than $4 \mathrm{~mm}$, i.c., the aluminurn cannot be used as a load bearing component.

Inclusion of aluminum in chamber components incurs a substantial price. The latter may be accommodated with substantial gamma-ray shielding of the aluminum components. Restrictions of access may only be reduoed by a substantial reduction in the amount of mctal incorporated into the MEA design. Maximum use of carbon or hydrocarbons, free of metallic impurities, will reduce the required waiting times for servicing MEA components.

\section{CONCLUSION}

Components of the MEA design have been developed. Computer simulations are nearly complete and experiments beginning. Structural and radiological calculations are currenty underway in order to establish necessary dimensions of the components and their cost. Probable distributions of shrapnel mass and velocity are being studied in order to design shrapnd mitigating defenses into the MEA design.

At the present time there appear to be no technological barriers to the construction of a suitable chamber for a $1000 \mathrm{M}$ ] ICF facility, although there are several difficult problems for which solutions are being developed. We have every reason to believe that the performance goals can be met and that the cost will be acceptable.

\section{ACKNOWLEDGMENTS}

In addition to those acknowledged in the text, the main thrust of this work has been guided by Neil Frank and John Wood worth at Lawrence Livermore National Laboratory (LLNL). Many additional ideas have been contributed by Monya Lane and Richard Warren at LLNL.

\section{REFERENCES}

1. E.F.PLECHATY,D.E.CULLEN, R.J.HOWERTON, TableS and Graphs of Photon Interaction Cross Sections, UCRL50400, Vol. 6. 1975.

2. L. WEBSTER, Kaman Sciences, private communication,

3. C. D. ORTH, "Frost as a First Wall for the JCF Laboratory Microfusion Facility", these proceedings.

4. M. J. MONSLER, W. R. MEJER, “A Carbon-Fiber BrushLike First Wall for the Laboratory Microfusion Facility", Ibid.

5. J. H. PITTS, J. C. WOODWORTH, M. TABAK, "Preventing Vaporization and Destructive Shock Waves in ICF TargetChamber First Walls", lbid.

6. R. R. PETERSON, J. I. MACFARLANE, I. I. BARRY, F. GONZALEZ, M. EL-AFIFY, G. A. MOSES, M. L. CORRADINI, "Inertial Confinement Fusion Reactor Cavity Analysis: Progress Report for the Period 1 July 1987 to 30 June 1988", University of Wisconsin, UWVFDM-765, July 1988. 
7. R.J.HARRACH,J.G.WOODWORTH,J.H. PITTS, M.GEE, "Mitigating Wall Damage in a Chamber Designed to Contain 1000-MJ Inertially Confined Fusion", UCRL-98284, 1988.

8. D. G. NILSON, J. G. WOODWORTH, "Final Optic Protection Designs for ICF Containment Chambers", these proceedings.

9. L. C. NORTHCLJFFE, R. F. SCHILLING, Nuclear Data Tables A?, 233 (1970).

10. M. T. TOBIN, M. S. SINGH, W. R. MEIER, "Radiological Safety Analysis of the Laboratory Microfusion Facility", these proceedings. 